\title{
Feasibility of Training Early Childhood Educators in a Community Child Care Setting Using a Caregiver-mediated Intervention for Toddlers with Autism Spectrum Disorder
}

\author{
Jessica Brian ${ }^{1,2}$, Kate Bernardi ${ }^{1}$, Erin Dowds ${ }^{1}$, Rachel Easterbrook ${ }^{1}$, Stacey MacWilliam ${ }^{3}$, Susan Bryson ${ }^{3}$ \\ ${ }^{1}$ Autism Research Centre, Bloorview Research Institute, Holland Bloorview Kids Rehabilitation Hospital; Toronto, \\ Ontario, Canada \\ ${ }^{2}$ Department of Paediatrics, University of Toronto; Toronto, Ontario, Canada \\ ${ }^{3}$ IWK Health Centre/Dalhousie University, Halifax, Nova Scotia, Canada \\ Correspondence: Jessica Brian, Autism Research Centre, Bloorview Research Institute, Holland Bloorview Kids \\ Rehabilitation Hospital; Toronto, Ontario, Canada.
}

Received: March 7, 2017

doi:10.11114/jets.v5i5.2345
Accepted: April 7, $2017 \quad$ Online Published: April 10, 2017

URL: https://doi.org/10.11114/jets.v5i5.2345

\begin{abstract}
Parent-mediated intervention programs have demonstrated benefits for toddlers with autism spectrum disorder (ASD). Interest is emerging in other community-level models, such as those that can be integrated into child care settings. These programs have the potential to reach a wide range of high-risk toddlers who spend the majority of their day in child care. The objective of this study was to translate and evaluate the feasibility of the Social ABCs caregiver-mediated intervention program into a community child care setting by training front-line early childhood educators (ECEs). Twenty-two ECEs attended a workshop on early intervention and ASD, and six ECEs and one special needs resource consultant received hands-on intervention training. Nineteen participants completed a workshop quiz, with significant mean improvement of $22.26 \%$ from pre- to post-workshop. After 12 weeks of live coaching (4 weeks in one case), participants attained a high level of fidelity in implementing the intervention strategies $(\geq 80 \%)$, which was maintained after a 3-month period of non-contact with the training team. Nine of ten specific strategies were mastered after the 12 -week training period, with only one technique failing to reach a mean fidelity level of $75 \%$. Findings reveal that the model of training front-line child care staff in a community child care setting is feasible using a relatively short-term training approach.
\end{abstract}

Keywords: Autism spectrum disorder, early childhood educators, training, early intervention, toddlers, community child care

\section{Introduction}

Autism spectrum disorder (ASD) is a heterogeneous neurodevelopmental condition that is estimated to occur in 1 out of 68 children (Christensen et al., 2016). Awareness of the signs and symptoms of emerging ASD and the importance of early intervention have become a focus of developmental clinical practice as developmental concerns are identified increasingly earlier in life. The importance of earlier identification and treatment of children with ASD is bolstered by evidence of improved outcomes with early behavioural intervention (see Reichow, 2012, for a review).

Examination of the development of infants and toddlers at high-risk for ASD (often siblings of children with ASD, who have elevated recurrence risk; Ozonoff et al., 2011) reveals a range of social-communication and behavioural challenges as early as 12 months of age in infants later diagnosed with ASD. These include delayed or impaired receptive and expressive language (Landa \& Garrett-Mayer, 2006; Mitchell et al., 2006), reduced use of early gestures (Barbaro \& Dissanayake, 2012; Jones, 2014; Mitchell et al., 2006), atypical object exploration, repetitive and stereotyped behaviour, diminished social attention, challenges with attentional control, and differences in temperament such as increasing irritability, intolerance of intrusions, and negative affect (Bryson et al., 2007; Bryson et al., under revision; Elsabbagh et al., 2013; Hutman, Chela, Gillespie-Lynch, \& Sigman, 2012; Ozonoff et al., 2008; Wan et al., 2013; Zwaigenbaum et al., 2005). By 18 months, high-risk children later diagnosed with ASD already have early impairments in several ASD-related areas such as orienting to name, responding to facial emotion, eye contact, transitions, reciprocal social 
smiling, reactivity, social interest and affect, motor control, and atypical motor and sensory behaviours (Barbaro \& Dissanayake, 2012; Brian et al., 2008; Jones, 2014). The early emergence of these behaviours, together with the urgency of early intervention makes early diagnosis particularly important. High-risk infant sibling studies reveal that diagnosis as early as 18 months of age is not only possible, but also relatively stable to age 3 (Ozonoff et al., 2015; Zwaigenbaum et al., 2016).

Robust evidence of early impairments in social interaction and communication, together with atypical behavioural patterns in ASD opens the door to the possibility of intervening very early in a child's development -before maladaptive patterns of behaviour become entrenched, and when brain development is most responsive to intervention. Studies have shown the promise of parent-mediated early intervention programs, particularly those that are based on applied behaviour analysis (ABA) - the technique that underlies evidence-based intervention for preschoolers and early school-aged children with ASD (Reichow, 2012). One such ABA-based approach, pivotal response treatment (PRT) aims to improve function in pivotal, or core areas of development -those that lead to overarching, 'collateral' changes in a range of other areas (Koegel, Koegel, Harrower, \& Carter, 1999). One key advantage of PRT is that it is well-suited to be conducted in naturalistic environments, or the most inclusive setting possible, as this allows for behaviours to be modified and elicited by natural environmental stimuli (Koegel et al., 1999). Parent-mediated PRT-based interventions, which target motivation and can be conducted in the home, have been shown to positively influence children's social responsiveness, behaviour, and communication (Brian et al., 2016; Coolican, Smith, \& Bryson, 2010; Koegel et al., 2003). Naturalistic ABA-based interventions are particularly suitable for toddlers, as they incorporate the systematic rigor required to effect change in individuals with ASD, but allow for the necessary flexibility required to optimize early development.

Parent/caregiver-mediated naturalistic ABA-based programs have demonstrated a range of benefits for toddlers with ASD (Baranek et al., 2015; Brian, Smith, Zwaigenbaum, Roberts, \& Bryson, 2016; Brian, Smith, Zwaigenbaum, \& Bryson, under revision; Green et al., 2015; Kasari, Gulsrud, Paparella, Hellemann, \& Berry, 2015; Kasari, Gulsrud, Wong, Kwon, \& Locke, 2010; Schertz, Odom, Baggett, \& Sideris, 2013; Vismara, Colombi, \& Rogers, 2009; Wetherby et al., 2014). The feasibility and efficacy of caregiver-mediated models points to the potential for other community-level intervention opportunities. Of particular interest are models that can be integrated into child care settings, which provide a rich social context for implementing the intervention strategies, and where many toddlers spend a large portion of their days. Training front-line child care providers in caregiver-mediated approaches has the potential to significantly extend the reach of early intervention; once trained, front-line providers can use their newly acquired skills with all children in their care both currently and in the future, should any social-communication challenges be observed. Despite an appetite for such community-based intervention opportunities, more work is needed with respect to training early childhood educators (ECEs) about the manifestations of ASD in toddlers, and about developmentally appropriate early intervention techniques for toddlers with emerging ASD or related social-communication challenges. Currently, there is considerable variability in professional training opportunities across early childhood education programs, which results in inconsistencies in the preparation that those working with children with special needs may have received by the time they begin their practical work. Many early childhood education trainees only receive a single placement for each year of their educational program and because not all child care services are inclusive of children with disabilities, trainees may not have had any experience with children with disabilities in their classrooms by the time they begin work (Underwood \& Killoran, 2009). Additionally, research has identified a lack of knowledge regarding children with disabilities, particularly those with ASD, amongst trainees in early childhood education programs (Barned et al., 2011; Underwood \& Killoran, 2009). These gaps extend to a lack of training regarding the benefits of different intervention approaches for children with ASD. In a survey of 15 ECE students, Barned et al. (2011) found that $73.3 \%$ did not believe that behaviour therapy was effective for children with ASD, and just under half were unaware of the importance of early intervention more generally. Furthermore, despite believing that all children should be included in general education classrooms, about half the respondents thought that only special educators should teach children with ASD or, if included in general education classrooms, many expected an expert to be in the classrooms to work with the child (Barned et al., 2011). Although many early childhood education trainees were familiar with the core impairments of ASD (e.g., social-communication challenges, language and sensory difficulties), there was limited understanding of the more complex symptoms or associated features such as eating difficulties and nonfunctional play (Barned et al., 2011; Johnson et al., 2012). Importantly, many trainees reported feeling unprepared for special education in their classrooms and stated they wished to learn more about ASD as they felt that this knowledge was necessary for their future as an educator (Barned et al., 2011; Maich \& Hall, 2014). Future ECEs also stated that their most common source of information regarding ASD was their educational curriculum, which points to the importance of including, and perhaps enhancing, training about interventions within the curriculum for early childhood education programs (Johnson et al., 2012). Killoran, Tymon, and Frempong (2007) found that children with ASD were the most highly represented group of children (25.7\%) with disabilities at child care centres in Toronto, Ontario. Additionally, nearly $22 \%$ of children with a 
disability had a speech and language disorder (Killoran et al., 2007). The high prevalence of children with ASD or language disorders in child care centres serves to underscore the need for an early intervention program designed to improve children's social-communication skills within such settings. Providing front-line child care staff with the skills to identify early signs of ASD and related social-communication challenges and to utilize early intervention strategies in their classroom is essential given the amount of contact these children and their families have with ECEs, and because this type of programming may benefit all children in the classroom, not just those with disabilities, through improving their communication skills (Vakil, Welton, O’Connor, \& Kline, 2009).

In many cases, families rely on individual (often private) therapies to enhance the communication and social development of their children with special needs. Reliance on individual therapies presents a time and financial burden, which many families cannot manage. Also, in many cases, a formal diagnosis is required to access specialized service, and long wait lists ensue. Although many of the early intervention programs developed using PRT strategies focus on parent implementation, some of these programs have been adapted or used in child care settings. A handful of training programs provided to ECEs in order to implement intervention strategies in their classrooms show success in increasing knowledge and understanding of ASD (Jocelyn, Casiro, Beattie, Bow, \& Kneisz, 1998). Video feedback and coaching sessions with ECEs have been associated with improved fidelity of implementation, team planning, and progress monitoring (Robinson, 2011; Strain \& Bovey II, 2011; Wilson, Dykstra, Boyd, \& Crais, 2012). With coaching, ECEs have also been successful at generalizing the acquired strategies to other students and activities in the classroom (Robinson, 2011). The benefits for children of these ECE-mediated interventions include gains in social behaviour, developmental level, vocabulary and communication, and decreased ASD symptoms (Boyd et al., 2014; Eapen, Črnčec, \& Walter, 2013; Strain \& Bovey II, 2011; Vivanti et al., 2014). However, many of these results come from time-intensive interventions, with the greatest effects shown after long periods of coaching and training (e.g., up to two years; Strain \& Bovey II, 2011). Ultimately, feedback from ECEs reveals that they feel more supported during coaching, more confident at utilizing these strategies in their classrooms, and that the children in their classrooms seem to benefit from the ECEs being trained (Meadan, Ostrosky, Zaghlawan, \& Yu, 2012; Robinson, 2011; Wilson et al., 2012).

\subsection{Caregiver-mediated Intervention Model and its Relevance to Child Care}

We previously developed and evaluated a caregiver-mediated intervention for toddlers with suspected or confirmed ASD (the Social ABCs; Brian, et al., 2016; Brian, et al., under revision). This intervention incorporates the principles and procedures of ABA, represented in the naturalistic context of PRT (Koegel \& Koegel, 2006; Koegel, Johnson, \& Dawson, 1989), and integrated within a responsive parenting framework (Landry, Smith, \& Swank, 2006). Two key areas of early impairment in ASD are targeted: positive emotion sharing and functional speech. With parents as mediators, this intervention has yielded gains in children's communication skills, shared positive affect between child and caregiver, and increased social orienting (Brian et al., 2016; Brian, et al., under review); this previous work demonstrates that training parents is a feasible, acceptable, and relatively low-resource way to improve child social communication and positive affect (Brian et al., 2016).

\subsection{Objectives}

The objective of this study was to translate and evaluate the feasibility of a caregiver-mediated intervention program in a community child care setting by training front-line early childhood staff. The focus was not on the efficacy of the intervention strategies, as this has been demonstrated elsewhere; our primary interest was in the ability of front-line staff to achieve fidelity of implementation in the child care context using a relatively brief training approach.

\section{Method}

\subsection{Research Design}

This study used a quantitative, pre-post design to evaluate change in knowledge and skills following a training workshop combined with 12 weeks of live, in-centre coaching.

\subsection{Setting and Partnerships}

This project was conducted through the Humber College School of Health Sciences, a community leader in educating ECEs in the Greater Toronto Area (Ontario, Canada). In addition to registered ECEs, every licensed child care program in the City of Toronto has an assigned special needs resource consultant who plays a critical role in the local public child care model. These consultants support the appropriate use of early screening tools, goal setting, targeted teaching strategies, and follow-up with front-line educators and parents. This project also involved Toronto Children's Services which partners with Humber College to train child care staff to support the inclusion of all children in licensed child care programs. Humber College has two full-time, not-for-profit, community based child care settings, funded by Ontario's Ministry of Health, which, in addition to providing inclusive, family-centered care for families within the community, serve as lab demonstration facilities for the Early Childhood Education Department in Humber's School of Health 
Sciences. Humber College Child Care Centre serves a culturally and socio-economically diverse population, with the immediate surrounding neighbourhood characterized by the following population data according to the 2011 Canadian census (Social Policy, Analysis \& Research Social Development, Finance \& Administration, 2014): 28\% single-parent families; 22\% low-income; 56\% English-speaking at home (none French); $42 \%$ English mother tongue (none French); 74\% visible minorities (primarily South Asian and Black).

\subsection{Ethics}

This study was approved by research ethics boards at both Humber College and Holland Bloorview Kids Rehabilitation Hospital.

\subsection{Participants}

\subsubsection{Consent}

Participants gave voluntary, informed consent to participate in the study; child care staff members were not required to participate, and were permitted to withdraw at any time without any negative consequences to their employment. Parents were also invited to provide consent for their child to be involved during the staff training (and to be videotaped during interactions with trainee staff). For children whose parents opted not to consent to the study, the training participants did not practice the intervention techniques with those children, and those children were not videotaped.

\subsubsection{Phase I (Training Workshop)}

Twenty-two participants voluntarily attended one of three identical workshops (offered at different times to accommodate varying staff availability). Workshops were attended by all trainees who participated in further training (direct coaching, described below), as well as program managers, other trainees, front-line staff, and faculty from the ECE program. This workshop represented a learning opportunity beyond the standard training curriculum (i.e., it did not replace existing curriculum).

\subsubsection{Phase II (Direct Coaching)}

Six registered ECEs and one special needs resource consultant took part in Phase II training. All participants had a college-level diploma in early childhood education. Experience in early childhood education ranged from 2-6 years for the front-line staff, and 20 years for the special needs resource consultant. Four of the seven trainees primarily spoke a language other than English in their homes, although all were fluent in English.

\section{Procedures}

\subsection{Phase I. Training Workshop}

A three-hour didactic workshop included education on topics such as (1) early signs of autism spectrum disorder in infants and toddlers, with curriculum based largely upon current research from baby siblings consortia (e.g., Jones et al., 2014; Zwaigenbaum et al., 2005); (2) an introduction to behavioural principles, (3) application of behavioural principles to toddlers with emerging/suspected ASD, and (4) an introduction to Pivotal Response Treatment and the Social ABCs. A 20-item knowledge-based quiz was developed for the workshop, to assess participants' knowledge immediately before and after workshop attendance. To maintain anonymity, participants were assigned a number to use for the pre- and post-workshop quiz, and numbers were not linked to participant identifying information in any way.

\subsection{Phase II. Didactic and Direct Coaching}

During the direct coaching phase, participants followed a schedule of visits over 12 weeks that involved didactic sessions with the research trainer, using our Social ABCS Manual, followed by in-vivo coaching while interacting with classroom students. Staff were provided with dedicated time (with staff coverage arranged for by the child care program managers) to learn the strategies, practice them with live coaching, receive feedback, and reflect on their learning goals on a $1: 1$ basis with their trainer.

Video-recorded data of staff interacting/playing with one of the children in their classroom were collected at three time-points: (1) at baseline, prior to attendance at the workshop and before any training; (2) post-training (week 12); and (3) at follow-up (week 24). The primary outcome measure was overall fidelity of implementation as evaluated by a reliable fidelity coder not directly involved in the training (SM), using a fidelity coding form adapted from Koegel and Koegel (2006) and validated for use in our parent-mediated intervention program.

\subsection{Analytic Approach}

\subsubsection{Hypotheses}

Anticipated outcomes included: (1) increased knowledge as measured by the workshop quiz; (2) significant increases in fidelity of implementation in the delivery of the intervention techniques from baseline to post-training, with 
maintenance at follow-up; and (3) achievement of a minimum of $75 \%$ overall fidelity of implementation, following the 12-week training, that would be maintained at follow-up 3 months later.

\subsubsection{Analyses}

To test the primary hypotheses, paired samples t-tests were conducted to compare: (1) pre- vs. post-workshop knowledge; and (2) baseline vs. post-training fidelity of implementation (overall mean, and for each of ten specific techniques, with corrected alpha $=.05 / 10=.005$ ). Fidelity of implementation (3) was examined at each time point to examine percent correct implementation. To further explore knowledge gaps and gains, exploratory analyses included twenty separate t-tests used to examine significance of increases in areas identified as knowledge gaps on the pre-workshop quiz (Bonferroni correction for multiple comparisons: $\alpha=0.05 / 20=0.0025$ ).

\section{Results}

\subsection{Phase I. Workshops}

Workshops were provided for a total of 22 attendees; 19 completed the workshop quiz, with significant mean improvement of $22.26 \%$ from pre- $(M=52.63 \%, S D=14.76)$ to post-workshop performance $(M=74.89 \%, S D=12.51)$, $t=7.57, p<.001$. Ten of the 20 quiz questions were correctly answered by more than $50 \%$ of respondents on the pre-workshop quiz. The remaining ten questions, identified as knowledge gaps, received fewer than $50 \%$ correct responses before the workshop. Paired-samples t-tests revealed significant increases from pre- and post-workshop quiz performance on several items: knowledge regarding the prevalence of ASD $(t=5.56, p<.001)$, average age of clinical ASD diagnosis $(t=4.98, p<.001)$, proto-declarative pointing $(t=4.47, p<.001)$, the basic principles of behavioural intervention $(t=4.42, p<.001)$, and some of the specific strategies of the Social ABCs. Positive trends towards significant improvement were identified for understanding the importance of natural learning environments $(t=2.54, p$ $<.02)$, how to elicit responses from children during behavioural intervention $(t=2.69, p<.02)$, and characteristics of positive reinforcement $(t=2.35, p<.03)$.

\subsection{Phase II. Direct Coaching}

Inter-rater reliability (IRR) was established for $30 \%$ of the video clips (IRR range: $81-92 \%$; $=86 \%$ ). A significant improvement emerged for overall fidelity of implementation from baseline $(M=47.08 \%, S D=11.51)$ to post-training $(M=85.50 \%, \mathrm{SD}=4.04), t=11.44, p<.001$. Overall implementation gains were maintained at follow-up $(M=86.30 \%$, $S D=4.19)$. Each trainee achieved fidelity $\geq 80 \%$ post-training and continued to implement above $80 \%$ fidelity at follow-up (see Figure 1); note that post-training data were obtained for one participant at week 4 rather than week 12, due to an unexpected leave, and she had already achieved $\geq 80 \%$ fidelity by that point. With alpha corrected for multiple analyses, three specific techniques showed significant improvement from baseline to post-training: shared control, contingent reinforcement, and reinforcement of all good attempts. At baseline, these strategies were only being used correctly $25.00 \%, 21.67 \%$, and $17.67 \%$ of the time, respectively (see Figure 2); post training, these rates increased to $82.50 \%, 80.83 \%$ and $67.00 \%$, respectively, $p$ 's $=.001,<.001$, and .002 , and were maintained at follow-up. Trends toward improvement were observed for all other strategies, but these failed to meet our stringent corrected alpha $(p$ 's range: .008- .112). Following training, all but one of the 10 strategies were being used at or beyond acceptable levels (i.e., 9 strategies $\geq 75 \%$ fidelity; 8 strategies $\geq 80 \%$ fidelity). The strategy least consistently used post training was reinforcement of all good attempts (67\% fidelity), but it is important to emphasize that use of this skill did increase significantly from a very low baseline rate (i.e., $<20 \%$ fidelity). 


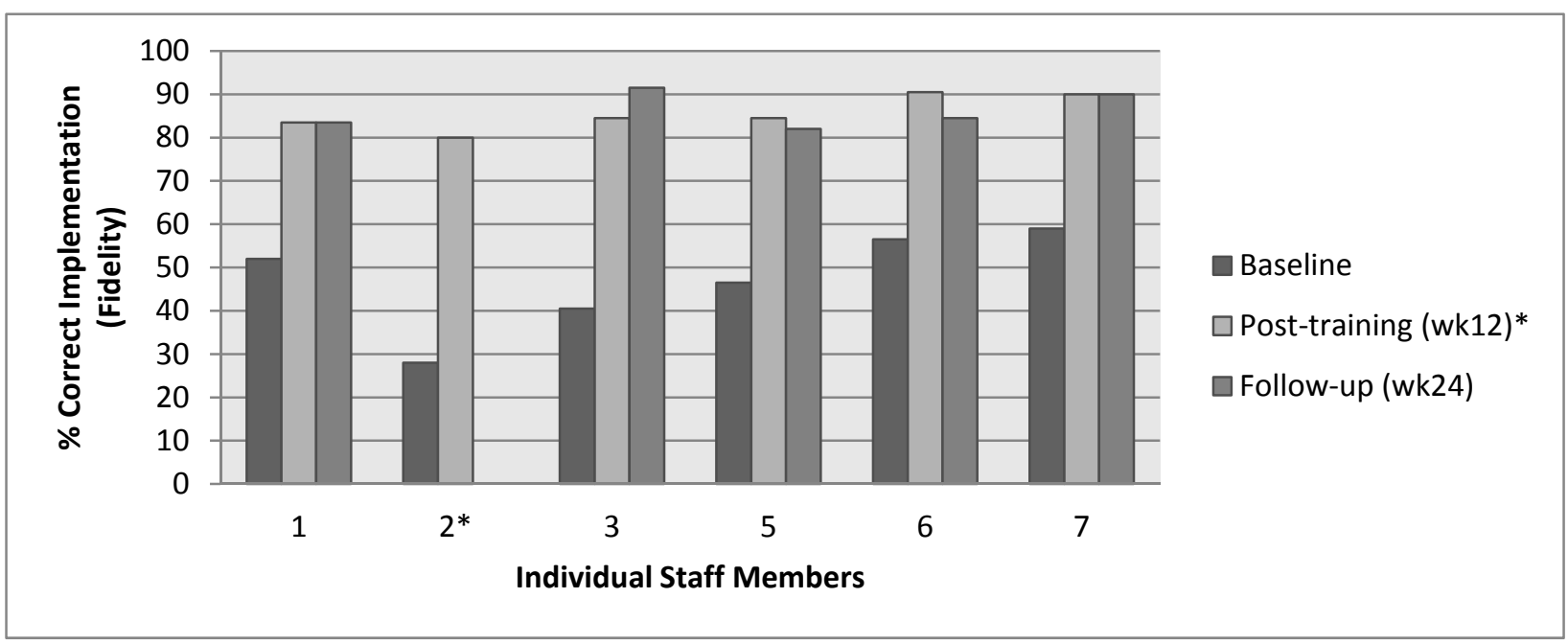

Figure 1. Correct implementation (\% fidelity overall) for each of 7 staff who received direct coaching, at baseline, post-training, and 3-month follow-up. *Note that, for participant \#2, post-training video was collected at week 4 due to an unforeseen absence; follow-up data were not available

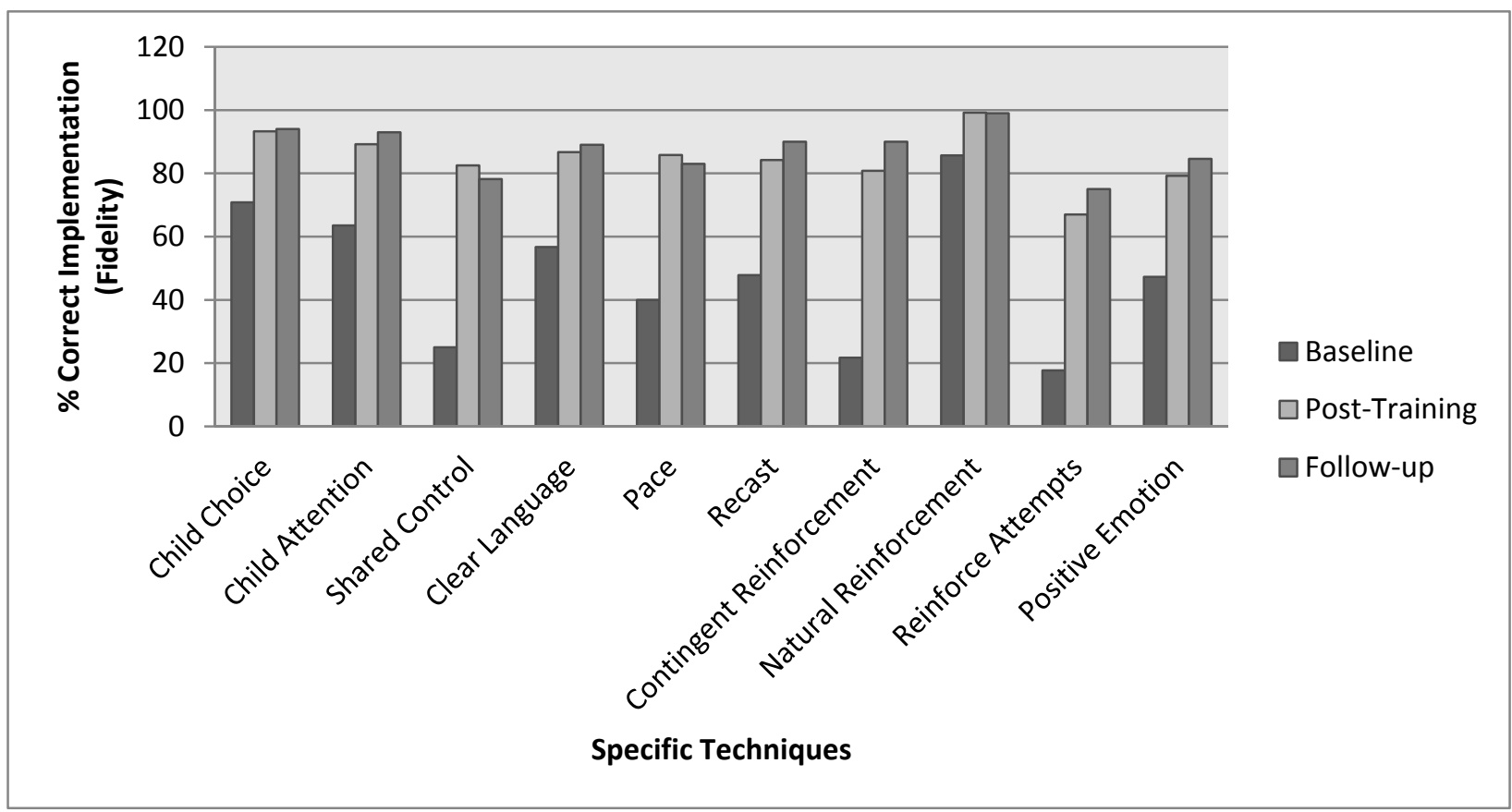

Figure 2. Mean correct implementation (\%) for each of ten main strategies at baseline, post-training, and 3-month follow-up

\section{Discussion}

Our findings reveal that the model of training front-line child care staff in a community child care setting is feasible using a relatively short-term training approach. After a single informational workshop, followed by 12 weeks of live coaching (beginning with two training sessions per week and then tapering to once a week by the third week of training), all participants learned and implemented the techniques to a high level of fidelity overall, which was maintained after a 3 -month period of non-contact with the training team. Nine of the ten specific strategies were mastered after the 12-week training period, with only one remaining below a $75 \%$ fidelity level. Some strategies were used with relative fluency even before training (e.g., allowing for child choice of activity, waiting for a child's attention before modelling, providing clear language models, and providing natural reinforcement). The specific strategy that appeared the most difficult to master was reinforcement of all good attempts, notably also the strategy least used at baseline. The importance of this strategy was initially demonstrated by Koegel, O’Dell, and Dunlap (1988), and highlighted as a key 
factor in maintaining children's motivation in the learning context. Detailed examination of video clips revealed several challenges to the use of this strategy, including trainees (1) waiting for a 'better' response (i.e., clearer, closer to a full word, vocalization paired with eye contact) before providing reinforcement, (2) missing child-initiated vocalizations, (3) accepting non-vocal responses (e.g., gestures without vocalization), (4) reinforcing despite the child not providing a response, or (5) getting interrupted by other children before being able to reinforce. Clearly, some of these challenges are particular to a busy child care setting, but others may be relatively easy to address through enhanced workshop content. Specifically, we plan to revise the workshop to include more discussion of the rationale and research evidence supporting the importance of reinforcing all good attempts, and will provide a range of examples of situations in which it has proven more difficult to implement, with group problem-solving to generate solutions.

Broadening the range of behaviourally-based, developmentally appropriate teaching strategies available to early childhood staff in a community child care presents an opportunity for the integration of intensive evidence-based intervention into the daily activities of very young children with early signs of ASD or related social-communication challenges. By training front-line caregivers to a high level of fidelity in implementing a naturalistic intervention for at-risk toddlers, they will ideally be able to continue using the intervention techniques throughout their day within the context of their existing curriculum and schedule, positively impacting any children in their care with, or at risk for, ASD or related social-communication challenges. Moreover, this increased knowledge and skill-set has the potential to benefit future cohorts of children cared for by the trained staff. This initial community translation of our caregiver-mediated intervention serves as the springboard for larger-scale training opportunities, designed to build community capacity. Equipping frontline caregivers with practical strategies to support social and communication development in at-risk children from 1 to 4 years of age increases access to enhancing environments earlier in development than might otherwise be available, potentially resulting in more children reaching their full potential. Intervening before a diagnosis is confirmed allows children to circumvent long waiting times for diagnostic assessment and interventions that are dependent on a formal diagnosis. An intervention that can be integrated into the child's daily learning environment in an inclusive way, and at the earliest stage of development (pre-diagnosis, at the first sign of risk) has the potential to have a considerable impact on their development.

This study has demonstrated the feasibility of training front-line early childhood educators in a caregiver-mediated model of intervention for toddlers with early social-communication challenges and/or emerging ASD. We used a 12-week training model adapted from previous work with parents, prefaced by a 3-hour introductory workshop. We do acknowledge that we had the advantage of having staff coverage provided during didactic training sessions, which may present a challenge for future roll-out of a program like ours in the future. However, given the high level of fidelity attained by at least one staff member very early in the training program, we might wish to evaluate a further abbreviated model in the future. Future work will need to evaluate the impact of such staff training on child outcomes; it may also be of interest to examine whether gains extend to other staff and children who are in the care of educators who have received enhanced training. Finally, we propose enhancing the educational curriculum across the post-secondary education sector for ECEs with increased focus on the early signs of emerging ASD, along with an introduction to ECE-mediated strategies that may help to support these at-risk toddlers.

\section{Conclusions}

Training front-line child care early educators in a caregiver-mediated intervention for toddlers with emerging ASD is feasible and presents an opportunity for the integration of intervention strategies into daily activities, thus allowing for a rich intervention experience at a very young age. Extending training beyond the family home to the child care setting has the potential to increase the reach of early intervention opportunities for at-risk children early in development. For children in full-time child care, ECEs provide a substantial amount of the child's caregiving during play activities, meals/snacks and other routines, as well as facilitating play and peer social interaction. Therefore, ECEs are in an ideal position to be the agents of change for toddlers in their care. By enhancing educators' skills in fostering communication development and affect sharing, they have the opportunity to integrate these strategies into their daily routines with the children in their care, resulting in increased intensity of intervention for the children in a context in which a significant proportion of their social and communication experiences occur.

\section{Acknowledgements}

This work was funded by Autism Speaks Canada, with additional support from the Bloorview Research Institute's Ward Summer Student award program (RE). We are extremely grateful to the Early Childhood Education Department in Humber College's School of Health Sciences (Joanne Tuck, RECE, ECEDH, Training Coordinator); Humber College Child Care Centres (Bridget Woodcock, RECE, B.Ed, M.Ed, Director); the City of Toronto Children's Services (Dick Winters, RECE, BA(H), Program Manager), and Jason Powell, Dean, School of Health Sciences, Humber College. We also gratefully acknowledge the participation of Cindy Stamoulakatos, RECE and Stephanie Moroni, RECE, both 
Resource Supervisors, Toronto Children's Services, Special Services Unit, and Humber Child Care Centre Manager, Marcie Miranda Gallo. We wish to thank the participating front-line registered ECEs, Asima Shahid, Gameli King, Stella Umana, Falisha Faria, and Andrea Burket, and special needs resource consultant, Larissa Kostevskii for their enthusiasm and openness to learning. Finally, we thank the parents of Humber's child care students for welcoming us into their children's child care centre.

\section{References}

Baranek, G. T., Watson, L. R., Turner-Brown, L., Field, S. H., Crais, E. R., Wakeford, L., ...Reznick, J. S. (2015). Preliminary efficacy of adapted responsive teaching for infants at risk of autism spectrum disorder in a community sample. Autism Research and Treatment. 2015. https://doi.org/10.1155/2015/386951

Barbaro, J., \& Dissanayake, C. (2012). Early markers of autism spectrum disorder in infants and toddlers prospectively identified in the Social Attention and Communication Study. Autism, 17(1), 64-86. https://doi.org/10.1177/1362361312442597

Barned, N. E., Knapp, N. F., \& Neuharth-Pritchett, S. (2011). Knowledge and attitudes of early childhood preservice teachers regarding the inclusion of children with autism spectrum disorder. Journal of Early Childhood Teacher Education, 32, 302-321. https://doi.org/10.1080/10901027.2011.622235

Boyd, B. A., Hume, K., McBee, M. T., Alessandri, M., Gutierrez, A., Johnson, L., ... \& Odom, S. L. (2014). Comparative efficacy of LEAP, TEACCH and non-model-specific special education programs for preschoolers with autism spectrum disorders. Journal of Autism and Developmental Disorders, 44, 366-380. https://doi.org/10.1007/s10803-013-1877-9

Brian, J. A., Smith, I. M., Zwaigenbaum, L., Bryson, S. E. (under review). Cross-site randomized control trial of the Social ABCs caregiver-mediated intervention for toddlers with autism spectrum disorder.

Brian, J. A., Smith, I. M., Zwaigenbaum, L., Roberts, W., \& Bryson, S. E. (2016). The Social ABCs caregiver-mediated intervention for toddlers with Autism Spectrum Disorder: Feasibility, acceptability, and evidence of promise from a multisite study. Autism Research, 9(8), 899-912. https://doi.org/10.1002/aur/1582

Brian, J., Bryson, S. E., Garon, N., Roberts, W., Smith, I. M., Szatmari, P., \& Zwaigenbaum, L. (2008). Clinical assessment of autism in high-risk 18-month-olds. Autism, 12(5), 433-456. https://doi.org/10.1177/1362361308094500

Bryson, S. E., Garon, N., McMullen, T. Brian, J., Zwaigenbaum, L., Armstrong, V., ... Szatmari, P. (under revision). Impaired disengagement of attention and its relationship to emotional distress in infants at high-risk for autism spectrum disorder.

Bryson, S. E., Zwaigenbaum, L., Brian, J., Roberts, W., Szatmari, P., Rombough, V., \& McDermott, C. (2007). A prospective case series of high-risk infants who developed autism. Journal of Autism and Developmental Disorders, 37, 12-24. https://doi.org/10.1007/s10803-006-0328-2

Christensen, D. L., Baio, J., Braun, K. V., Bilder, D., Charles, J., Constantino, J. N., ... Yeargin-Allsopp, M. (2016). Prevalence and Characteristics of Autism Spectrum Disorder Among Children Aged 8 Years - Autism and Developmental Disabilities Monitoring Network, 11 Sites, United States, 2012. MMWR Surveill Summ, 65, 1-23. https://doi.org/10.15585/mmwr.ss6503al

Coolican, J., Smith, I. M., \& Bryson, S. E. (2010). Brief parent training in pivotal response treatment for preschoolers with autism. Journal of Child Psychology and Psychiatry, 51(12), 1321-1330. https://doi.org/10.1111/j.1469-7610.2010.02326.x

Eapen, V., Črnčec, R., \& Walter, A. (2013). Clinical outcomes of an early intervention program for preschool children with autism spectrum disorder in a community group setting. BMC Pediatrics, 13(3). https://doi.org/10.1186/1471-2431-13-3

Elsabbagh, M., Fernandes, J., Webb, S. J., Dawson, G., Charman, T., Johnson, M. H., \& British Autism Study of Infant Siblings Team. (2013). Disengagement of visual attention in infancy is associated with emerging autism in toddlerhood. Biological Psychiatry, 74(3), 189-194. https://doi.org/10.1016/j.biopsych.2012.11.030

Green, J., Charman, T., Pickles, A., Wan, M. W., Elsabbagh, M., Slonims, V., ... Jones, E. J. (2015). Parent-mediated intervention versus no intervention for infants at high risk of autism: A parallel, single-blind, randomised trial. Lancet Psychiatry, 2(2), 133-140. https://doi.org/10.1016/S2215-0366(14)00091-1

Hutman, T., Chela, M. K., Gillespie-Lynch, K., \& Sigman, M. (2012). Selective visual attention at twelve months: Signs of autism in early social interactions. Journal of Autism and Developmental Disorders, 42, 487-498. 
https://doi.org/10.1007/s10803-011-1262-5

Jocelyn, L. J., Casiro, O. G., Beattie, D., Bow, J., \& Kneisz, J. (1998). Treatment of children with autism: A randomized controlled trial to evaluate a caregiver-based intervention program in community day-care centres. Developmental and Behavioral Pediatrics, 19(5), 326-334. https://doi.org/10.1097/00004703-199810000-00002

Johnson, P., Porter, K., \& MacPherson, I. (2012). Autism knowledge among pre-service teachers specialized in children birth through age five: Implications for health education. American Journal of Health Education, 43(5), 279-287. https://doi.org/10.1080/19325037.2012.10599246

Jones, E. J. H., Gliga, T., Bedford, R., Charman, T., \& Johnson, M. H. (2014). Developmental pathways to autism: A review of prospective studies of infants at risk. Neuroscience and Biobehavioral Reviews, 39(100), 1-33. https://doi.org/10.1016/j.neubiorev2013.12.001

Kasari, C., Gulsrud, A. C., Wong, C., Kwon, S., \& Locke, J. (2010). Randomized controlled caregiver mediated joint engagement intervention for toddlers with autism. Journal of Autism and Developmental Disorders, 40(9), 1045-1056. https://doi.org/10.1007/s10803-010-0955-5

Kasari, C., Gulsrud, A., Paparella, T., Hellemann, G., \& Berry, K. (2015). Randomized comparative efficacy study of parent-mediated interventions for toddlers with autism. Journal of consulting and clinical psychology, 83(3), 554. https://doi.org/10.1037/a0039080

Killoran, I., Tymon, D., \& Frempong, G. (2007). Disabilities and inclusive practices within Toronto preschools. International Journal of Inclusive Education, 11(1), 81-95. https://doi.org/10.1080/13603110500375473

Koegel, L. K., Koegel, R. L., Harrower, J. K., \& Carter, C. M. (1999). Pivotal response intervention I: Overview of approach. Research and Practice for Persons with Severe Disabilities, 24(3), 174-185. https://doi.org/10.2511/rpsd.24.3.174

Koegel, R. L., \& Koegel, L. K. (2006). Pivotal response treatments for autism: Communication, social, and academic development. Baltimore, MD: Brookes Publishing.

Koegel, R. L., Johnson, J., \& Dawson, G. (1989). Motivating language use in autistic children. Autism: Nature, diagnosis, and treatment, 310-325.

Koegel, R. L., Koegel, L. K., \& Brookman, L. I. (2003). Empirically supported pivotal response interventions for children with autism. In A. E. Kazdin (Ed.), Yale University School of Medicine, \& Child Study Center (Eds.), Evidence-based Psychotherapies for Children and Adolescents: Evidence-based Psychotherapies for Children and Adolescents (pp. 341-357). New York, NY: Guilford Press.

Koegel, R.L., O'Dell, M., \&and Dunlap, G. (1988). Producing speech use in nonverbal autistic children by reinforcing attempts. Journal of Autism and Developmental Disorders, 18(4), 525-538. https://doi.org/10.1007/BF02211871

Landa, R., \& Garrett-Mayer, E. (2006). Development in infants with autism spectrum disorders: A prospective study. Journal of Child Psychology and Psychiatry, 47(6), 629-638. https://doi.org/10.1111/j.1469-7610.2006.01531.x

Landry, S. H., Smith, K. E., \& Swank, P. R. (2006). Responsive parenting: establishing early foundations for social, communication, and independent problem-solving skills. Developmental psychology, 42(4), 627. https://doi.org/10.1037/0012-1649.42.4.627

Maich, K., \& Hall, C. (2014). Are we ready? Early childhood educator students and perceived preparedness for school-based special education. Canadian Children, 39(3), 42-52.

Meadan, H., Ostrosky, M. M., Zaghlawan, H. Y., \& Yu, S. (2012)2012. Using coaching with preschool teachers to support the social skills of children with and without autism spectrum disorders. International Journal of Early Childhood Special Education, 4(2), 74-94.

Mitchell, S., Brian, J., Zwaigenbaum, L., Roberts, W., Szatmari, P., Smith, I., \& Bryson, S. (2006). Early language and communication development of infants later diagnosed with autism spectrum disorder. Developmental and Behavioral Pediatrics, 27(2), S69-S78. https://doi.org/10.1097/00004703-200604002-00004

Ozonoff, S., Macari, S., Young, G. S., Goldring, S., Thompson, M., \& Rogers, S. J. (2008). Atypical object exploration at 12 months of age is associated with autism in a prospective sample. Autism, 12(5), 457-472. https://doi.org/10.1177/1362361308096402

Ozonoff, S., Young, G. S., Carter, A., Messinger, D., Yirmiya, N., Zwaigenbaum, L., ... Hutman, T. (2011). Recurrence risk for autism spectrum disorders: a Baby Siblings Research Consortium study. Pediatrics, 128(3), e488-e495. https://doi.org/10.1542/peds.2010-2825 
Ozonoff, S., Young, G. S., Landa, R. J., Brian, J., Bryson, S., Charman, T., ... Zwaigenbaum, L. (2015). Diagnostic stability in young children at risk for autism spectrum disorder: a baby siblings research consortium study. Journal of Child Psychology and Psychiatry, 56(9), 988-998. https://doi.org/10.1111/jcpp.12421

Reichow, B. (2012). Overview of meta-analyses on early intensive behavioral intervention for young children with autism spectrum disorders. Journal of Autism and Developmental Disorders, 42(4), 512-520. https://doi.org/10.1007/s10803-011-1218-9

Robinson, S. E. (2011). Teaching paraprofessionals of students with autism to implement pivotal response treatment in inclusive school settings using a brief video feedback training package. Focus on Autism and Other Developmental Disabilities, 26(2), 105-118. https://doi.org/10.1177/1088357611407063

Schertz, H. H., Odom, S. L., Baggett, K. M., \& Sideris, J. H. (2013). Effects of joint attention mediated learning for toddlers with autism spectrum disorders: An initial randomized controlled study. Early Childhood Research Quarterly, 28(2), 249-258. https://doi.org/10.1016/j.ecresq.2012.06.006

Social Policy, Analysis \& Research Social Development, Finance \& Administration. (2014). 2011 Neighbourhood Census/National Household Survey. City of Toronto.

https://www1.toronto.ca/City\%20Of\%20Toronto/Social\%20Development,\%20Finance\%20\&\%20Administration/ Neighbourhood\%20Profiles/pdf/2011/pdf4/cpa22.pdf

Strain, P. S., \& Bovey II, E. H. (2011). Randomized, controlled trial of the LEAP model of early intervention for young children with autism spectrum disorders. Topics in Early Childhood Special Education, 31(3), 133-154. https://doi.org/10.1177/0271121411408740

Underwood, K., \& Killoran, I. (2009). Early intervention practice and research in Ontario, Canada: Listening to the field. Journal of Early Childhood Teacher Education, 30, 298-305. https://doi.org/10.1080/10901020903084439

Vakil, S., Welton, E., O'Connor, B., \& Kline, L. S. (2009). Inclusion means everyone! The role of the early childhood educator when including young children with autism in the classroom. Early Childhood Education Journal, 36, 321-326. https://doi.org/10.1007/s10643-008-0289-5

Vismara, L. A., Colombi, C., \& Rogers, S. J. (2009). Can one hour per week of therapy lead to lasting changes in young children with autism? Autism, 13(1), 93-115. https://doi.org/10.1177/1362361307098516

Vivanti, G., Paynter, J., Duncan, E., Fothergill, H., Dissanayake, C., \& Rogers, S. J. (2014). Effectiveness and feasibility of the Early Start Denver Model implemented in a group-based community childcare setting. Journal of Autism and Developmental Disorders, 44, 3140-3153. https://doi.org/10.1007/s10803-014-2168-9

Wan, M. W., Green, J., Elsabbagh, M., Johnson, M., Charman, T., Plummer, F., \& the BASIS Team. (2013). Quality of interaction between at-risk infants and caregiver at 12-15 months is associated with 3-year autism outcome. The Journal of Child Pscyhology and Psychiatry, 54(7), 763-771. doi: 10.1111/jepp.12032

Wetherby, A. M., Guthrie, W., Woods, J., Schatschneider, C., Holland, R. D., Morgan, L., \& lord, C. (2014). Parent-implemented social intervention for toddlers with autism: An RCT. Pediatrics, 134(6), 1084-1093. https://doi.org/10.1542/peds.2014-0757

Wilson, K. P., Dykstra, J. R., Watson, L. R., Boyd, B. A., \& Crais, E. R. (2012). Coaching in early education classrooms serving children with autism: A pilot study. Early Childhood Education Journal, 40, 97-105. https://doi.org/10.1007/s10643-011-0493-6

Zwaigenbaum, L., Bryson, S. E., Brian, J., Smith, I. M., Roberts, W., Szatmari, P., ... Vaillancourt, T. (2016). Stability of diagnostic assessment for autism spectrum disorder between 18 and 36 months in a high - risk cohort. Autism Research, 9(7), 790-800. https://doi.org/10.1002/aur.1585

Zwaigenbaum, L., Bryson, S. E., Rogers, T., Roberts, W., Brian, J., \& Szatmari, P. (2005). Behavioural manifestations of autism in the first year of life. International Journal of Developmental Neuroscience, 23, 143-152. https://doi.org/10.1016/j.ijdevneu.2004.05.001

\section{Copyrights}

Copyright for this article is retained by the author(s), with first publication rights granted to the journal.

This is an open-access article distributed under the terms and conditions of the Creative Commons Attribution license which permits unrestricted use, distribution, and reproduction in any medium, provided the original work is properly cited. 